\title{
Development of Stabilized Magnetite Nanoparticles for Medical Applications
}

\author{
Ioana Lavinia Ardelean, Luric Bogdan Niculae Stoencea, Denisa Ficai, Anton Ficai, \\ Roxana Trusca, Bogdan Stefan Vasile, Gheorghe Nechifor, and Ecaterina Andronescu
}

Faculty of Applied Chemistry and Material Science, Politehnica University of Bucharest, 1-7 Gh Polizu Street, 011061 Bucharest, Romania

Correspondence should be addressed to Denisa Ficai; denisaficai@yahoo.ro

Received 12 March 2017; Accepted 27 April 2017; Published 11 June 2017

Academic Editor: Vidyadhar Singh

Copyright (c) 2017 Ioana Lavinia Ardelean et al. This is an open access article distributed under the Creative Commons Attribution License, which permits unrestricted use, distribution, and reproduction in any medium, provided the original work is properly cited.

\begin{abstract}
We report a facile method to synthesize magnetite nanoparticles with mesoporous structure by coprecipitation method using different stabilizing agents like salicylic acid, glutamic acid, and trichloroacetic acid. The stabilizing agents were used to prevent the aggregation of the magnetite nanocrystals and to obtain stable nanostructures even in the biological environment. The structure and morphology of magnetic nanocrystals were determined using X-ray diffraction (XRD), Fourier Transform Infrared (FTIR) spectroscopy, Brunauer-Emmett-Teller (BET) analysis, infrared (IR) spectra, scanning and transmission electron microscopy (SEM and TEM), high-resolution transmission electron microscopy (HRTEM), and selected area electron diffraction (SAED). The results reveal important differences between these magnetic nanoparticles (MNPs), which are mainly attributed to the stabilizing agents. The smallest nanoparticles were obtained in the presence of trichloroacetate ions. The mechanism of formation of these suprastructures is strongly correlated with the end functional groups of the stabilizing agent. Thus, the obtained nanoparticles are potential candidates for contrast agents as well as targeted carrier for specific diseases, especially cancer.
\end{abstract}

\section{Introduction}

Synthesis and characterization of porous materials have attracted considerable attention in recent years due to their industrial and biomedical applications: heavy metals removal, sensors, catalysis, magnetic recording and separation, photocatalysis, pigments, ferrofluids, magnetic resonance imaging, hyperthermia drug delivery, and so on [16]. Mesoporous iron oxides such as $\mathrm{Fe}_{3} \mathrm{O}_{4}$ and $\gamma-\mathrm{Fe}_{2} \mathrm{O}_{3}$ and $\mathrm{CoFe}_{2} \mathrm{O}_{4}$ are successfully used in the field of magnetic fluids, catalysis, biotechnology/biomedicine, magnetic resonance imaging, and magnetic recording devices because of their paramagnetism, biocompatibility, and safety [7-11]. Owing to their large surface area and well-defined pore structure and size, the lack of toxicity, and the possibility of targeted accumulation in the desired tissue, mesoporous $\mathrm{Fe}_{3} \mathrm{O}_{4}$ nanospheres are extensively used as targeted drug delivery systems [12].

Various techniques have been developed to synthesize some important transition metal oxides (such as $\mathrm{Fe}_{3} \mathrm{O}_{4}$ and
$\mathrm{CoFe}_{2} \mathrm{O}_{4}$ ) with various interior porous architecture (simple hollow spheres, core-shell and mesoporous structures [1315]) using coprecipitation method [16], pyrolysis, hydrothermal reaction [17], microwave-assisted synthesis [18], and the thermal decomposition of organometallic compounds [1922].

Liu et al. [23] prepared Palladium- (Pd-) loaded aminogroup functionalized mesoporous $\mathrm{Fe}_{3} \mathrm{O}_{4}$ nanoparticles ( $\mathrm{Pd} @ \mathrm{Fe}_{3} \mathrm{O}_{4}$ ) by a simple solvothermal method using ethanol as solvent. They show that the $\mathrm{Pd} @ \mathrm{Fe}_{3} \mathrm{O}_{4}$ modified the glassy carbon electrode (GCE) which then exhibited excellent electrochemical catalytic activities towards dopamine (DA) due to the synergetic effect between $\mathrm{Pd}$ and $\mathrm{Fe}_{3} \mathrm{O}_{4}$.

Kumari et al. [24] synthesized magnetite nanospheres with hollow interiors using a simple, one-pot, and templatefree solvothermal method with ferric chloride as the iron precursor, for the purpose of using this mesoporous nanosphere to remove heavy metals from waste water. The Langmuir adsorption capacities of the magnetic nanospheres were 9 and $19 \mathrm{mg} / \mathrm{g}$ for $\mathrm{Cr}^{6+}$ and $\mathrm{Pb}^{2+}$, respectively. 
Xia et al. [25] synthesized high-quality mesoporous $\mathrm{Fe}_{3} \mathrm{O}_{4}$ nanocages (MFONs) with a mesoporous structure and highly uniform dispersion by a facile complex-coprecipitation method at $100^{\circ} \mathrm{C}$ with addition of triethanolamine and ethylene glycol. They show that when used as an anode material for rechargeable lithium-ion batteries, MFONs anode presents high specific capacities and excellent cycling performance at high and low current rates thanks to the unique mesoporous cage-like structure and high specific surface area $\left(133 \mathrm{~m}^{2} / \mathrm{g}\right)$, which may offer large electrode/electrolyte contact area for the electron conduction and $\mathrm{Li}^{+}$storage.

The surface modification of the magnetic materials is essential for most of the chemical and biological applications and the performances of these materials can be designed by proper surface modification. Among the properties of interest, biocompatibility, biostability, and internalization are especially studied in the literature. It is well known that magnetite dispersibility and chemical stability in biological media are improved by functionalization with PEG (polyethylene glycol), dextran, albumin, chitosan, PVA (polyvinyl alcohol), PLGA (poly(lactic-co-glycolic acid)), and so on [26], but only a very limited number of studies present the functionalization of these nanoparticles with bifunctional small molecules like aminoacids, hydroxyacids, or haloacids [27, 28]. These bifunctional stabilizing small agents can be essential in allowing a better internalization of the nanoparticles inside the cells (especially when using aminoacids as functionalization agents), but they do not improve the dispersibility (because dispersability is ensured by the existence of highly charged groups such as citrate where three carboxylic groups are available for repulsive purposes). At this moment, a special attention is paid to folic acid (vitamin 12), a specific aminoacid, which proved to have a good internalization capacity for the magnetic nanoparticles, and it even allows a targeted delivery inside the tumoral cells [29-32].

The aminoacid or hydroxyacid based coating over the magnetic core offers the premises of high biocompatibility and an improvement in the capacity of internalization of these nanoparticles. In this study we report a facile method to synthesize magnetite nanoparticles with mesoporous structure by coprecipitation method using different stabilizing agents: salicylic acid, glutamic acid, and trichloroacetic acid. The very different structure and potential biological activity of the three stabilizing agents is important in designing new magnetic agents with desired properties. After the coating of the magnetic core, glutamic acid still has a free carboxyl group while salicylic acid has a hydroxyl group, each group being able to further bind molecules onto the surface [33]. Glutamic acid also acts as a powerful dispersing agent (like citrate) because of the net negative surface charge of the resulting nanostructures. The role of different stabilizing agents from the point of view of crystallinity, pore diameter, and surface area was analyzed. In order to determine the structure and morphology, the as-synthesized mesoporous $\mathrm{Fe}_{3} \mathrm{O}_{4}$ was characterized by powder X-ray diffraction (XRD), Fourier Transform Infrared (FTIR) spectroscopy, BrunauerEmmett-Teller (BET), infrared (IR) spectra, scanning and transmission electron microscopy (SEM and TEM), highresolution transmission electron microscopy (HRTEM), and selected area electron diffraction (SAED).

\section{Experimental Details}

2.1. Materials and Methods. The main precursors used for the preparation of mesoporous magnetite are iron (III) chloride $\left(\mathrm{FeCl}_{3}\right)$ (Sigma-Aldrich), ammonium iron (II) sulfate hexahydrate $\left(\mathrm{Fe}\left(\mathrm{NH}_{4}\right)_{2}\left(\mathrm{SO}_{4}\right)_{2} 6 \mathrm{H}_{2} \mathrm{O}\right)$ (Silal Trading), sodium hydroxide $(\mathrm{NaOH})$ (Silal Trading), salicylic acid $\left(\mathrm{C}_{6} \mathrm{H}_{7} \mathrm{O}_{3}\right)$ (Chimactiv), glutamic acid (Sigma-Aldrich), trichloroacetic acid (Carlo Erba RP ACS), and distilled water.

Mesoporous magnetite nanoparticles were prepared by precipitation method [34] with different stabilizing agents: salicylic acid, glutamic acid, and trichloro acetic acid. The precipitation bath was obtained as follows. First of all, the sodium hydroxide solution $(10 \mathrm{~g} \mathrm{NaOH} / 250 \mathrm{~mL}$ solution) was obtained and then mixed with further $2.5 \mathrm{~g}$ of the stabilizing agent, under vigorous mechanical stirring at room temperature. The $\mathrm{pH}$ of the precipitation bath was set at 10 11 with hydroxide solution. The precursors solution $(8.4520 \mathrm{~g}$ $\mathrm{Fe}\left(\mathrm{NH}_{4}\right)_{2}\left(\mathrm{SO}_{4}\right)_{2} * 6 \mathrm{H}_{2} \mathrm{O}$ and $6.9920 \mathrm{~g} \mathrm{FeCl}_{3}$ in $100 \mathrm{ml}$ distilled water) was sprayed into the obtained precipitation bath, under continuous mechanical stirring. The spraying rate was set at about $2-3 \mathrm{~mL} / \mathrm{min}$. After precipitation, the mixture was placed in the ultrasonic bath for 30 minutes; then the mesoporous magnetite was filtered and washed, whenever needed, with distilled water until neutral $\mathrm{pH}$ and chloride-free filtrate were obtained. Finally, the synthesized mesoporous magnetite was dried in an vacuum oven at a temperature of $60^{\circ} \mathrm{C}$ (Figure 1) [34]. Based on the above presented procedure, magnetite $\left(\mathrm{Fe}_{3} \mathrm{O}_{4}\right)$, magnetite with salicylic acid $\left(\mathrm{Fe}_{3} \mathrm{O}_{4} @ \mathrm{SAL}\right)$, magnetite with glutamic acid $\left(\mathrm{Fe}_{3} \mathrm{O}_{4} @ \mathrm{GLU}\right)$, and magnetite with trichloroacetic acid $\left(\mathrm{Fe}_{3} \mathrm{O}_{4} @ \mathrm{TCA}\right)$ have been obtained.

The mesoporous magnetite nanoparticles were characterized by XRD, FTIR, SEM, TEM, and BET.

IR spectroscopy was performed on a Nicolet iS 50 FTIR spectrometer equipped with a broad range DTGS detector providing high-sensitivity infrared information from $4000 \mathrm{~cm}^{-1}$ to $100 \mathrm{~cm}^{-1}$ and an integral diamond ATR unit. The system is configured with the built-in iS50 ATR module and an iS50 ABX Automated Beamsplitter Exchanger. The spectra were recorded in ATR mode over the wave number range of $400-4000 \mathrm{~cm}^{-1}$, with a resolution of $4 \mathrm{~cm}^{-1}$ coadding 64 spectra for improving the quality of the spectra. For a better identification of the peaks, the obtained spectra were resolved using a Gaussian-Lorentzian peak resolve procedure assuming a linear baseline.

Morphological information was obtained by scanning electron microscopy of the gold-coated specimens. The analysis has been performed using a QUANTA INSPECT F SEM device equipped with a field emission gun (FEG) with a resolution of $1.2 \mathrm{~nm}$ and with an X-ray energy dispersive spectrometer (EDS).

$\mathrm{X}$-ray diffraction analysis was carried out on a Panalytical X'Pert Pro MPD equipment, with a $\mathrm{CuK}_{\alpha}$ radiation, over a scan range of $2 \theta$ of $10-90^{\circ}$. 


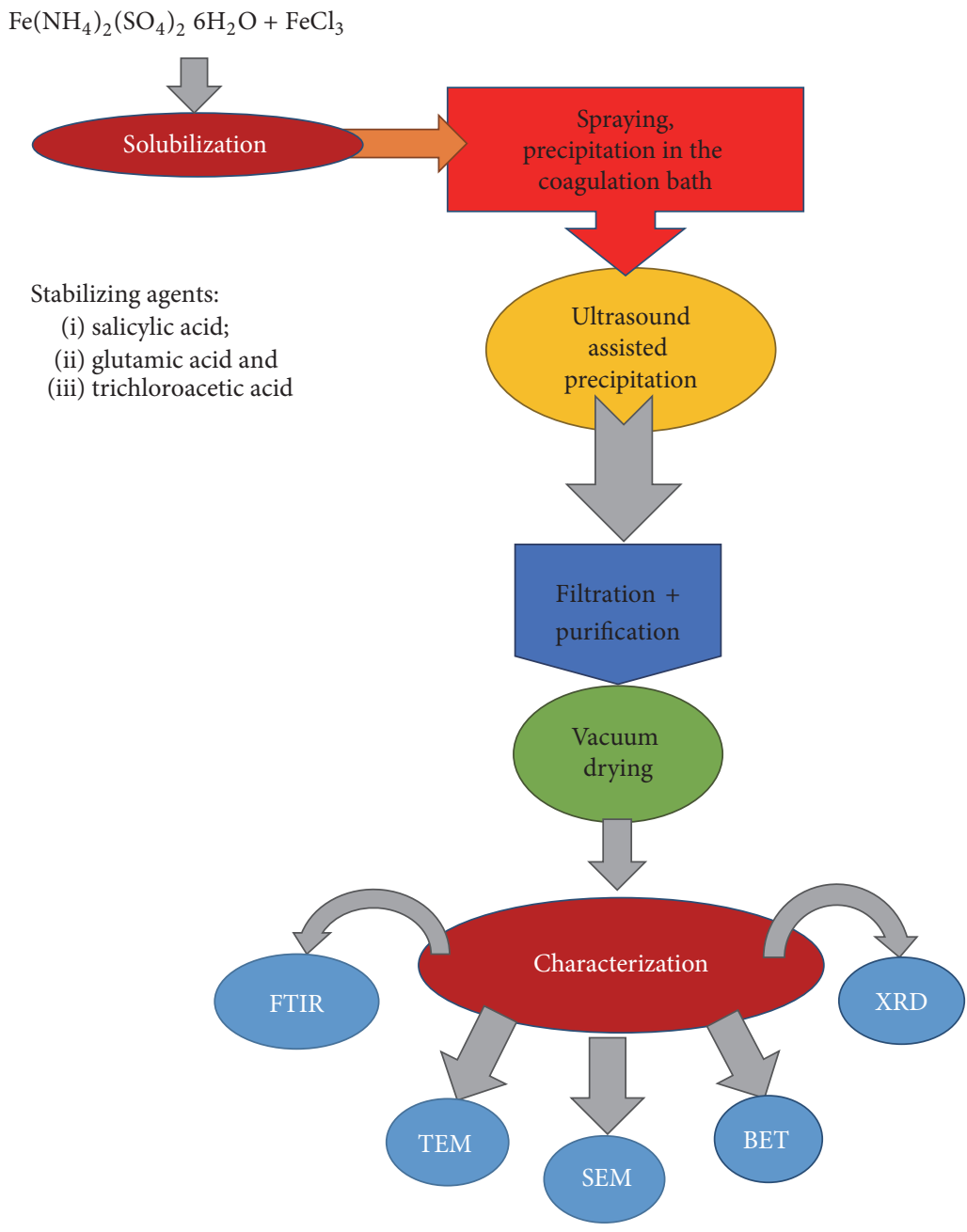

FIGURE 1: Preparation flowchart of magnetic nanoparticles.

TEM analyses were performed on a Tecnai G2 F30 S-TWIN high-resolution transmission electron microscope (HR-TEM) equipped with energy dispersive spectroscopy (EDS) as well as a selected area electron diffraction detector (SAED). The microscope was operated in transmission mode at $300 \mathrm{kV}$; TEM point resolution was $2 \AA$ and line resolution was $1 \AA$.

The Brunauer-Emmett-Teller (BET) analysis was performed on a Micrometrics Gemini V surface area and pore size analyzer.

\section{Results and Discussion}

3.1. Complex Thermal Analysis. The complex thermal analysis (Figure 2) was recorded in order to quantify the amount of stabilizing agent retained on the magnetic nanostructures. It can be seen that, among the three stabilizing agents, the lowest affinity to the magnetic core belongs to GLU $(0.54 \%)$ and the highest belongs to TCA (7.28\%) while SAL exhibits intermediary affinity (2.50\%). Based on the TG data, the strong flattening of the XRD peaks of the $\mathrm{Fe}_{3} \mathrm{O}_{4} @$ TCA can be explained because of the high content of the stabilizing agent
(7.28\%) while in the case of $\mathrm{Fe}_{3} \mathrm{O}_{4} @ \mathrm{SAL}$ (containing 2.50\% stabilizing agent) the flattering is less significant (plane 422 disappears while plane 220 is strongly flattered). In the case of GLU stabilized magnetic nanostructures, the peaks are even stronger which can mean that the crystallization process was even better compared with the pure $\mathrm{Fe}_{3} \mathrm{O}_{4}$ sample. All these masses were determined at $600^{\circ} \mathrm{C}$.

The differential thermal analysis reveals a stabilization effect of the salicylic acid, the most intense exothermic peak of pure magnetite ( 538.7 being shifted to $549.5^{\circ} \mathrm{C}$ ) while in both the other cases this peak is shifted to lower temperature (498.0 and $525.2^{\circ} \mathrm{C}$ ).

3.2. X-Ray Diffraction. X-ray diffraction was used in order to establish the formation of magnetite as a pure phase. The XRD patterns (Figure 3 ) of the synthesized mesoporous MNPs present only the characteristic peaks of magnetite [34] even if the crystallinity and the crystallite size depend on the used stabilizing agent. The main crystallization planes of inverse spinel magnetic crystals can be clearly identified by XRD ((111), (9220), (311), (400), (422), (511), and (440)), their relative intensity indicating a nonpreferential crystallization 


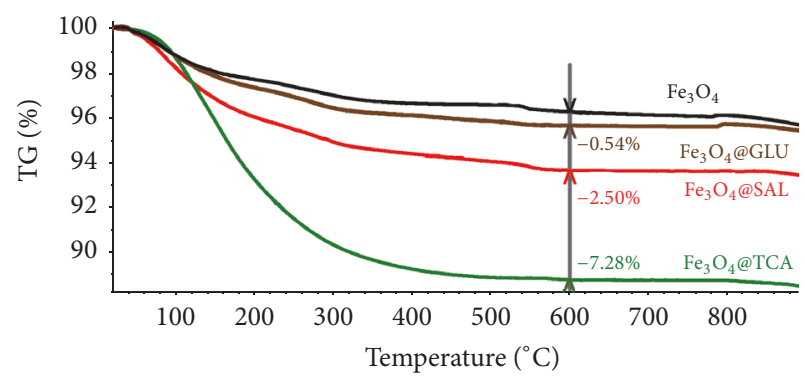

(a)

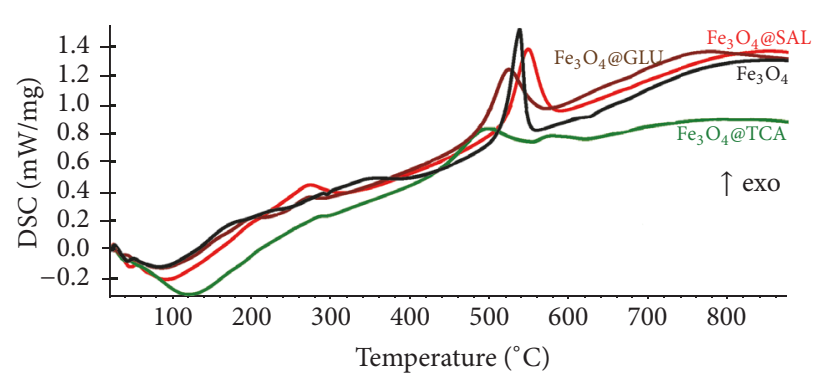

(b)

Figure 2: Complex thermal analysis of $\mathrm{Fe}_{3} \mathrm{O}_{4}, \mathrm{Fe}_{3} \mathrm{O}_{4} @ \mathrm{GLU}, \mathrm{Fe}_{3} \mathrm{O}_{4} @ S A L$, and $\mathrm{Fe}_{3} \mathrm{O}_{4} @ \mathrm{TCA}$ : (a) thermogravimetric analysis and (b) differential thermal analysis.
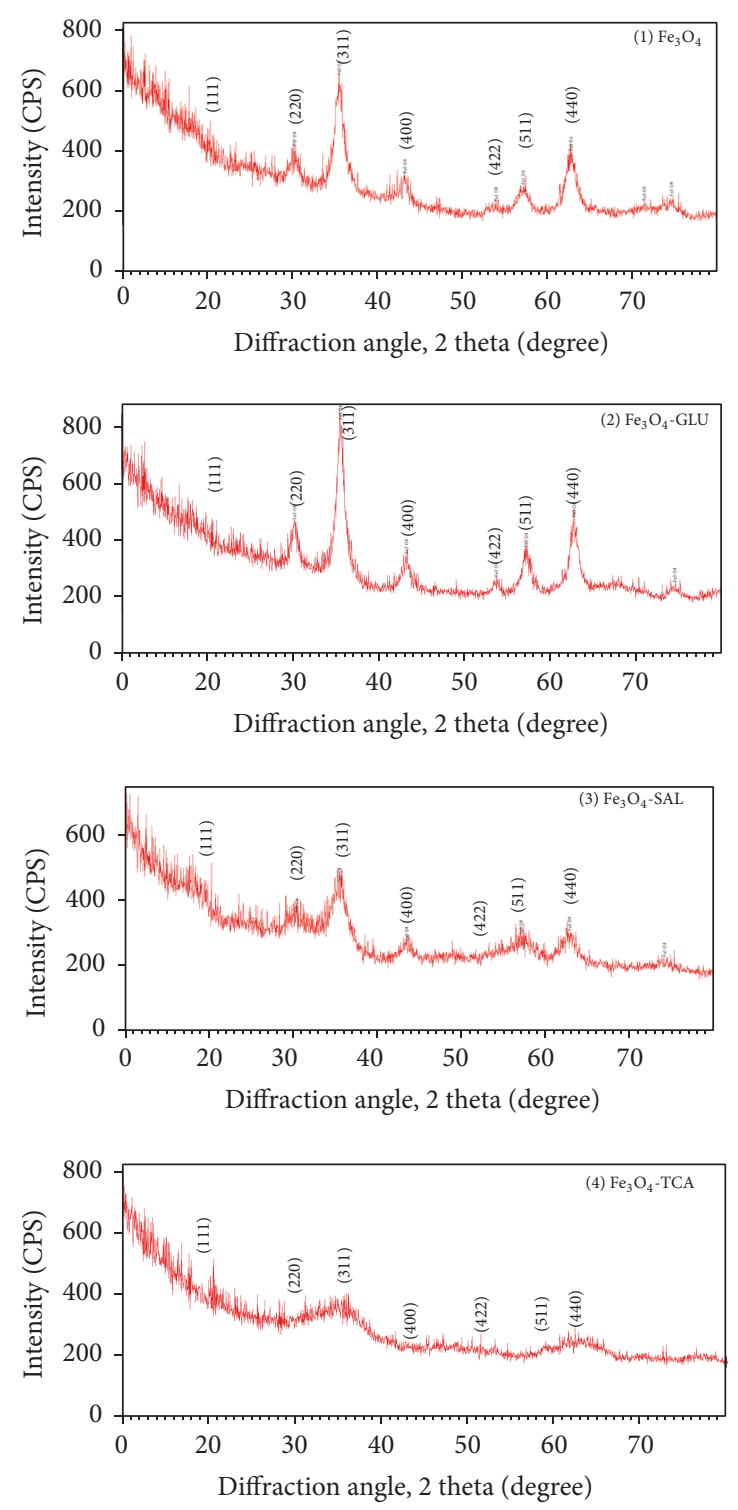

FIGURE 3: XRD patterns of the synthesized nanoparticles: (1) $\mathrm{Fe}_{3} \mathrm{O}_{4}$, (2) $\mathrm{Fe}_{3} \mathrm{O}_{4} @ G L U,(3) \mathrm{Fe}_{3} \mathrm{O}_{4} @ S A L$, and (4) $\mathrm{Fe}_{3} \mathrm{O}_{4} @ \mathrm{TCA}$. according to the literature [35] and ASTM 0075-1609. The average crystallite size is calculated using the Debye-Scherrer equation: $D=k \lambda / \beta \cos \theta$, where $k=0: 95$ is Scherrer's constant, $\lambda$ is the $\mathrm{X}$-ray wavelength, $\beta$ is the full width at halfmaximum, and $\theta$ is the Bragg diffraction angle. Based on this equation, the crystallite size (using the reflection plane (311), which can be measured for all the samples) was found to be 8.8, 11.3, 6.1, and $2.5 \mathrm{~nm}\left(\mathrm{Fe}_{3} \mathrm{O}_{4}, \mathrm{Fe}_{3} \mathrm{O}_{4} @ \mathrm{GLU}, \mathrm{Fe}_{3} \mathrm{O}_{4} @ S A L\right.$, and $\mathrm{Fe}_{3} \mathrm{O}_{4} @ T C A$, resp.). The XRD patterns of $\mathrm{Fe}_{3} \mathrm{O}_{4}$ and $\mathrm{Fe}_{3} \mathrm{O}_{4} @ \mathrm{GLU}$ are similar, with almost the same shape and comparative peaks intensity which means that comparative crystallinity and crystallite size are obtained. In the case of $\mathrm{Fe}_{3} \mathrm{O}_{4} @ \mathrm{SAL}$, the characteristic diffraction peaks decrease as intensity, while, in the case of $\mathrm{Fe}_{3} \mathrm{O}_{4} @ \mathrm{TCA}$, even the main peak of magnetite could not be clearly identified.

3.3. FTIR. The FTIR data reveal some differences between the spectra of the samples, especially compared with pure magnetite (Figure 4). Based on the literature data [35], the main bands of magnetite corresponding to the vibration of $\mathrm{Fe}^{3+} / \mathrm{Fe}^{2+}-\mathrm{O}^{2-}$ in tetrahedral and octahedral sites in the magnetite appear at $\sim 400$ and $568 \mathrm{~cm}^{-1}$. It can be seen that both $\mathrm{Fe}_{3} \mathrm{O}_{4} @ S A L$ and $\mathrm{Fe}_{3} \mathrm{O}_{4} @ G L U$ exhibit high similitude with the pure magnetite, most probably because of the low content of the stabilizing agent ( 0.54 and 2.50 for GLU and SAL, resp.). In the case of the sample obtained in the presence of trichloroacetate, the strong band from $\sim 540 \mathrm{~cm}^{-1}$ is only visible as a shoulder. The explanation is related to the presence of a high amount of trichloroacetate $(7.28 \%$ based on the thermogravimetric data), as stabilizing agent covering the magnetite core. The presence of the trichloroacetate can be clearly identified after deconvolution between 400 and $1700 \mathrm{~cm}^{-1}$, based on its main bands centered close to that of sodium trichloroacetate (based on the HR Aldrich FTIR Collection Edition II library): 685 (new peak), 710 (new peak), 723, 738 (new peak), and $845 \mathrm{~cm}^{-1}$ (Figure 4, insert). The shifting of these peaks is a proof of the strong interaction between magnetite core and trichloroacetate shell, along with the strong decrease of the strong peak of magnetite 
TABLE 1: BET data of the synthesized MNPs samples.

\begin{tabular}{lccc}
\hline Sample code & Samples name & Specific surface area $S_{\mathrm{BET}}\left(\mathrm{m}^{2} / \mathrm{g}\right)$ & Average pore size $D_{\mathrm{BET}}(\mathrm{nm})$ \\
\hline $\mathrm{Fe}_{3} \mathrm{O}_{4}$ reference* & $\mathrm{Fe}_{3} \mathrm{O}_{4}$ & $156.0278 \mathrm{~m}^{2} / \mathrm{g}$ & $5.7466 \mathrm{~nm}$ \\
$\mathrm{Fe}_{3} \mathrm{O}_{4} @$ citrate* & $\mathrm{Fe}_{3} \mathrm{O}_{4} @$ citrate & $257.15 \mathrm{~m}^{2} / \mathrm{g}$ & $2.8075 \mathrm{~nm}$ \\
$\mathrm{Fe}_{3} \mathrm{O}_{4} @ \mathrm{SAL}$ & $\mathrm{Fe}_{3} \mathrm{O}_{4} @$ salicylic acid & $204.7198 \mathrm{~m}^{2} / \mathrm{g}$ & $5.2712 \mathrm{~nm}$ \\
$\mathrm{Fe}_{3} \mathrm{O}_{4} @ \mathrm{GLU}$ & $\mathrm{Fe}_{3} \mathrm{O}_{4} @$ glutamic acid & $129.5527 \mathrm{~m}^{2} / \mathrm{g}$ & $8.3597 \mathrm{~nm}$ \\
$\mathrm{Fe}_{3} \mathrm{O}_{4} @ \mathrm{TCA}$ & $\mathrm{Fe}_{3} \mathrm{O}_{4} @$ trichloroacetic acid & $287.7533 \mathrm{~m}^{2} / \mathrm{g}$ & $3.4475 \mathrm{~nm}$ \\
\hline
\end{tabular}

${ }^{*}$ Data published in [34].

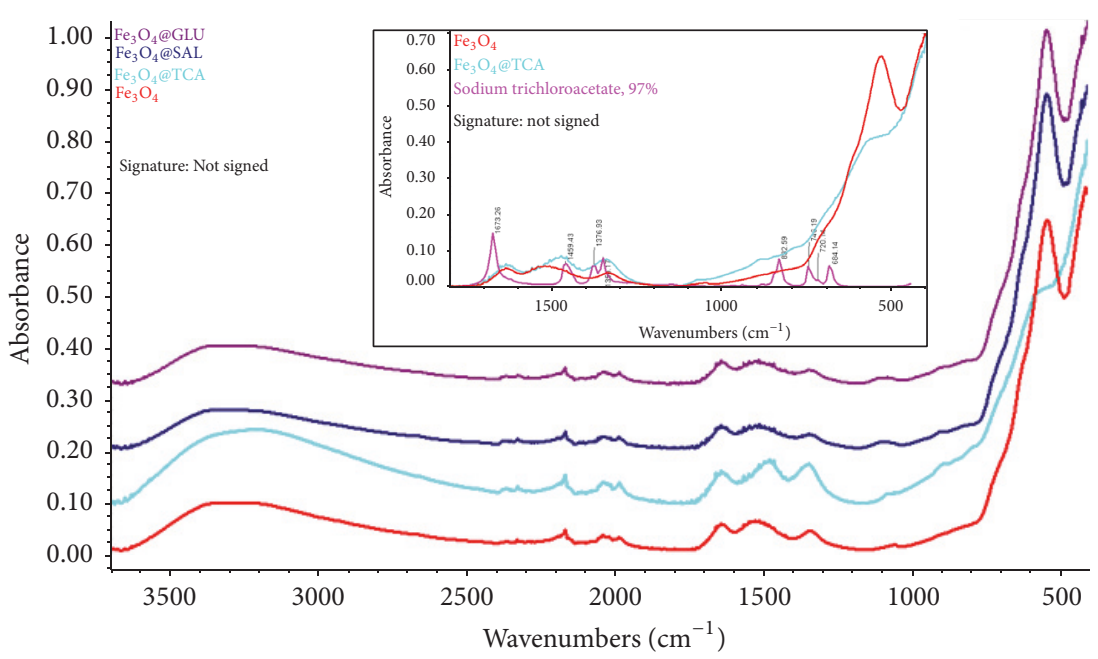

FIgURE 4: FTIR spectra of the magnetic samples: $\mathrm{Fe}_{3} \mathrm{O}_{4}, \mathrm{Fe}_{3} \mathrm{O}_{4} @ \mathrm{TCA}, \mathrm{Fe}_{3} \mathrm{O}_{4} @ S A L$, and $\mathrm{Fe}_{3} \mathrm{O}_{4} @ \mathrm{GLU}$; insert represents an overlay of $\mathrm{Fe}_{3} \mathrm{O}_{4}$, $\mathrm{Fe}_{3} \mathrm{O}_{4} @ \mathrm{TCA}$, and sodium trichloroacetate, over the region of $400-1800 \mathrm{~cm}^{-1}$.

from $\sim 532 \mathrm{~cm}^{-1}$ and the strong decrease of the Roentgen interferences characteristic for magnetite.

The most representative SEM images recorded at 50 (100) $\mathrm{kx}$ and $400 \mathrm{kx}$ are presented in Figure 5. At high magnification, the nanostructured nature of these materials can be visualized. The morphology of $\mathrm{Fe}_{3} \mathrm{O}_{4} @ \mathrm{GLU}$ and $\mathrm{Fe}_{3} \mathrm{O}_{4} @ S A L$ is similar to that of bare $\mathrm{Fe}_{3} \mathrm{O}_{4}$ while the $\mathrm{Fe}_{3} \mathrm{O}_{4} @ \mathrm{TCA}$ exhibits different morphology, perhaps due to the increasing content of the organic stabilizing agent and smaller particle size. These differences will be further resolved by (HR)TEM.

The TEM images were used to determine the size and morphology of the synthesized MNPs (Figure 6). The TEM images of the samples reveal some particularities. First of all, in all cases, the fine particles are strongly agglomerated because of the attractive forces between the magnetic nanoparticles. Based on the HRTEM images, the size and shapes of the nanoparticles can be evaluated. In the case of bare magnetite, spherical nanoparticles can be identified, the diameter of these nanoparticles being between 3 and $20 \mathrm{~nm}$. In the case of $\mathrm{Fe}_{3} \mathrm{O}_{4} @ \mathrm{GLU}$, two kinds of nanoparticles can be identified. The spherical nanoparticles have similar characteristics with those of pure magnetite but some rodlike nanoparticles can be also identified, their length reaching up to $50 \mathrm{~nm}$, while the diameter is less than $10 \mathrm{~nm}$. Based on the crystallite size determined by Debye-Scherrer equation, a good consistency between the TEM and XRD data can be concluded if considering also the capping effect induced by the stabilizing agent [36] except for the case of the rodlike structures identified in $\mathrm{Fe}_{3} \mathrm{O}_{4} @ G L U$ where these particles contain tens of crystallites. In the case of $\mathrm{Fe}_{3} \mathrm{O}_{4} @ S A L$ and $\mathrm{Fe}_{3} \mathrm{O}_{4} @ \mathrm{TCA}$, the size of the spherical nanoparticles is decreasing dramatically compared with the previous MNPs; the use of TCA as stabilizing agent induces the most important size reduction and, thus, has the best ability to stabilize the magnetite and can be correlated with the higher amount of stabilizing agent linked onto the magnetite core (7.28\%). This conclusion is also supported by the SAED patterns of the four MNPs. In all cases, the selected area electron diffraction shapes confirm the formation of very fine nanoparticles, especially when TCA is used, the polycrystalline structure of the cubic spinel magnetic crystals being clearly highlighted, being in good accordance with the XRD data [37].

BET analysis was used to characterize the obtained mesoporous MNPs from the point of view of surface area. From the point of view of the average pore size and specific surface area, the stabilizing agents play an important role. According to Table 1, the pure magnetite has a specific surface area of $\sim 156 \mathrm{~m}^{2} / \mathrm{g}$ and an average pore size of $5.75 \mathrm{~nm}$ while the use of salicylic acid leads to an increased specific surface area and practically no change of the pore size; the use of glutamic acid leads to an important decrease of the specific surface area and an increase of the pore size while the use of trichloroacetic acid leads to a strong increase of the specific surface area (almost two times higher specific surface area 

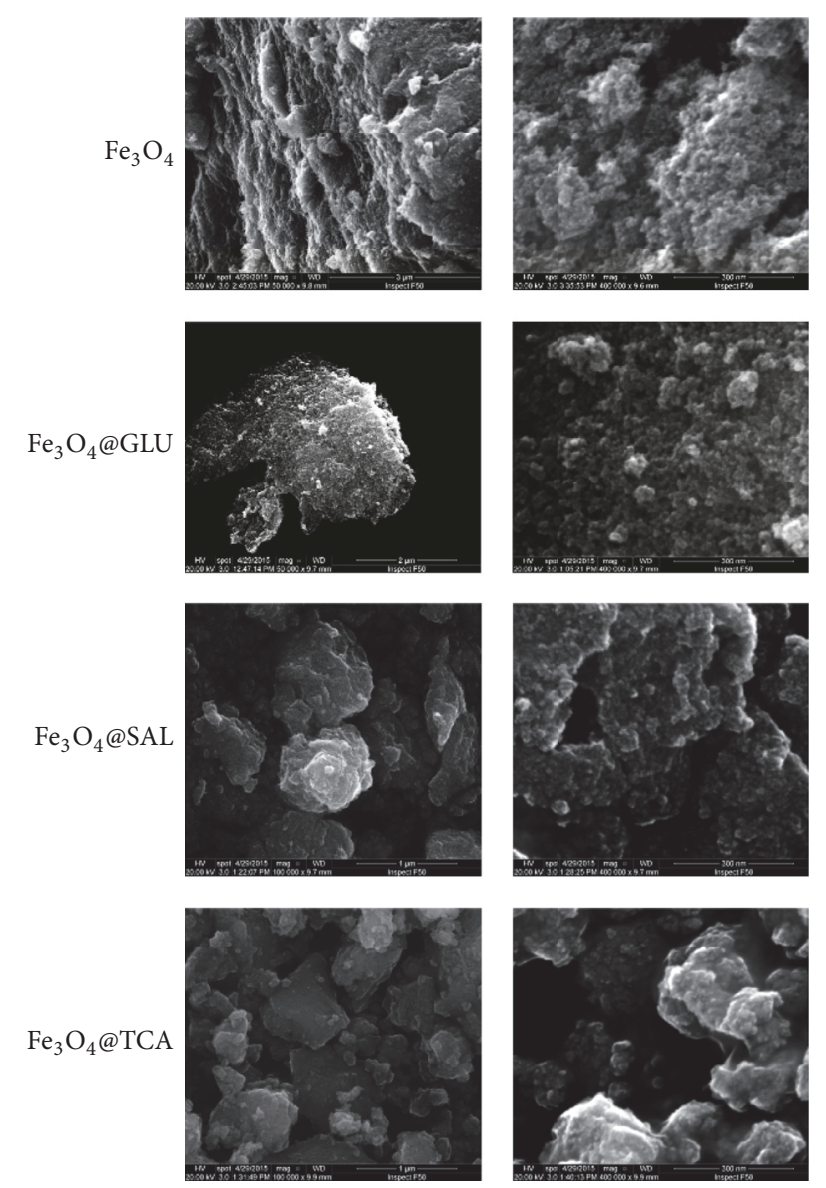

FIGURE 5: SEM images of the stabilized and nonstabilized magnetic nanoparticles obtained by coprecipitation.

compared with reference magnetite) and a corresponding decrease of the average pore size, down to $3.45 \mathrm{~nm}$. The different behaviors are explained based on the different chemical structure of the three stabilizing agents and different amount of stabilizing agent adsorption onto the magnetic crystals. The strongest stabilization effect is ensured by TCA which conducts to a higher specific surface area being in good agreement with the TEM images (especially visible at low magnification, the first image of each sample). Compared with the well-established $\mathrm{Fe}_{3} \mathrm{O}_{4} @$ citrate superparamagnetic iron oxide nanoparticles, it can be concluded that TCA can ensure even better stabilization effect and the specific surface area can be improved by $10 \%$ [34].

The mechanisms of the formation of the $\mathrm{Fe}_{3} \mathrm{O}_{4} @$ stabilizing agent is strongly dependent on some factors, the most important being the nature of the stabilizing agent and its concentration and $\mathrm{pH}$. When the stabilizing agent is TCA, the single possibility of self-assembling is presented in Figure 7(a), carboxylate group being absorbed onto the magnetite core surface, while the trichloromethyl groups are oriented to the outer region of the core@shell structure. Between these core@shell individual structures hydrophobic interactions occur, thus leading to agglomerates. In the case of glutamic acid, as well as salicylic acid, the formation
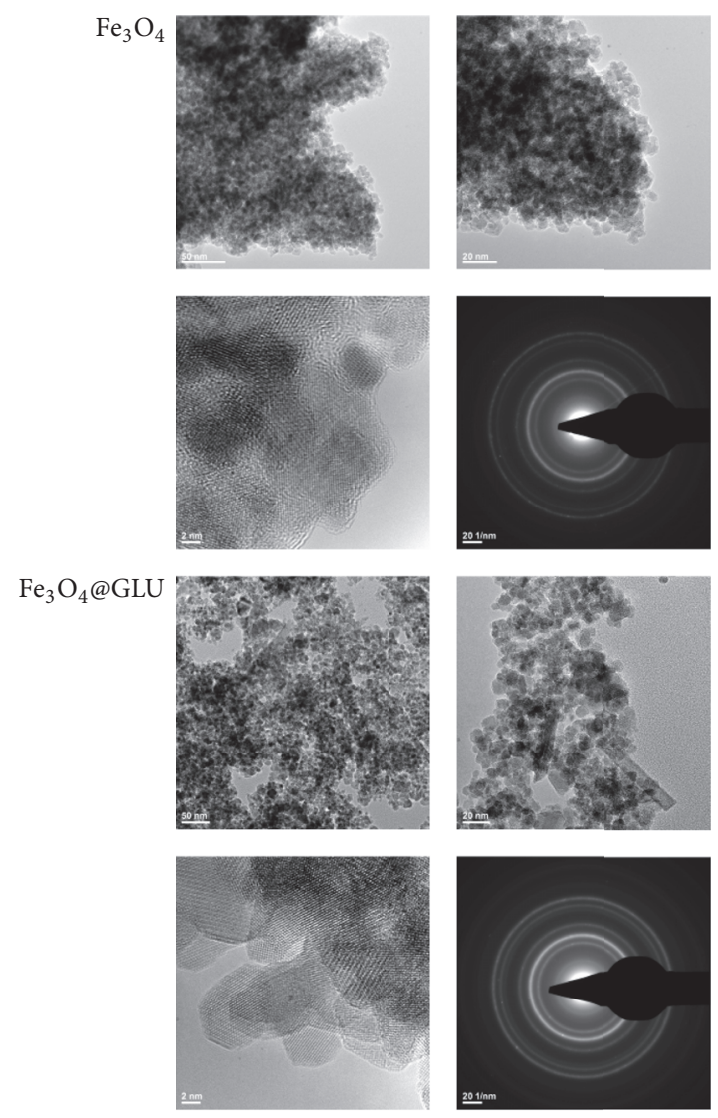

$\mathrm{Fe}_{3} \mathrm{O}_{4} @ \mathrm{SAL}$
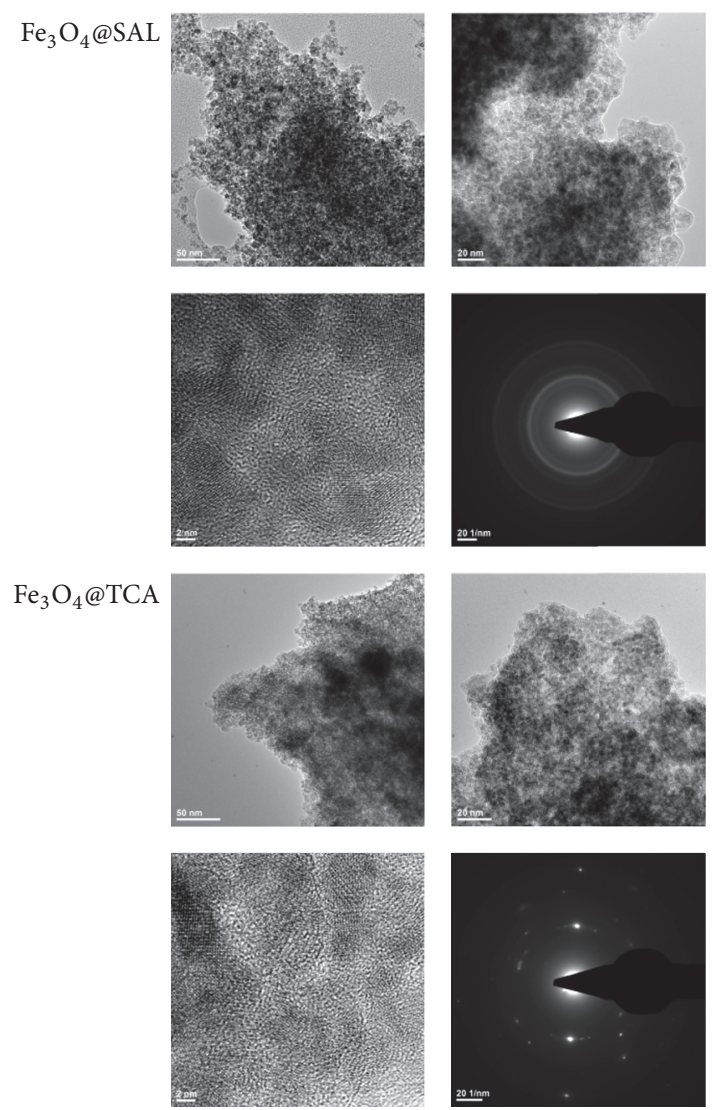

FIGURE 6: TEM, HRTEM, and SAED patterns of the bare magnetite and stabilized MNPs. 


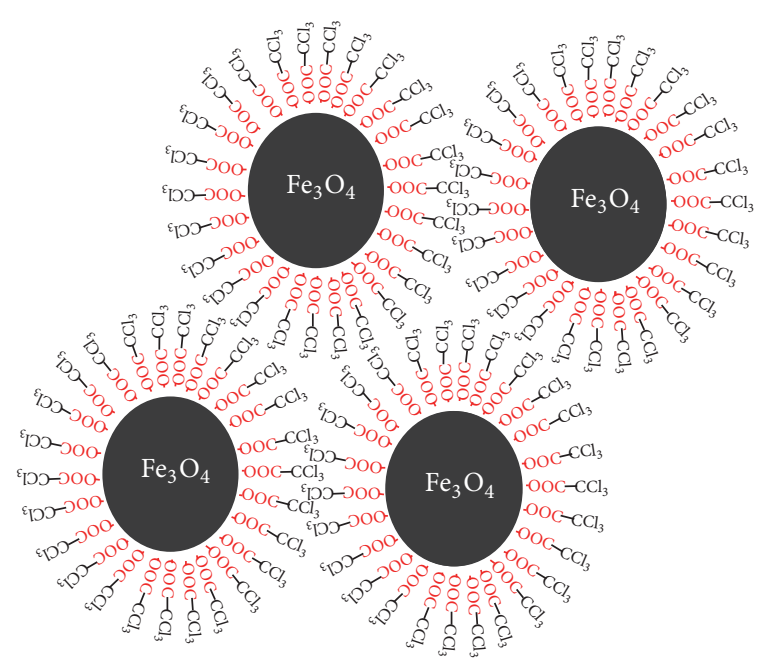

(a)

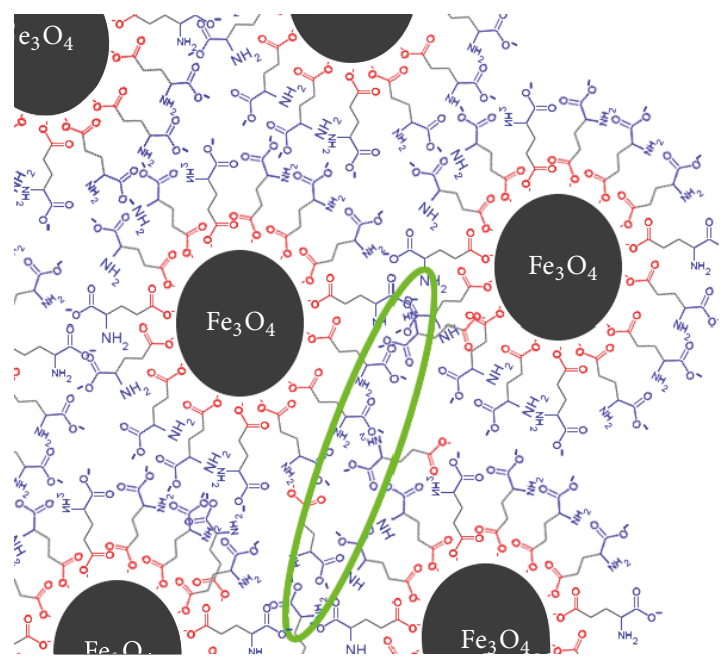

(b)

Figure 7: Magnetite based suprastructures induced by stabilizing agents.

of $\mathrm{Fe}_{3} \mathrm{O}_{4} @ \mathrm{GLU}$ and $\mathrm{Fe}_{3} \mathrm{O}_{4} @ \mathrm{SAL}$ leads to the existence of multiple functional groups of the stabilizing agent, therefore allowing additional interactions between these moieties. So, along with the formation of the similar core@shell structures and agglomerates (assuming that $\mathrm{COOH}$ is in its anionic form and ammonium in its zero-valent form, namely, $\mathrm{NH}_{2}$ ), as presented in the case of TCA, the additional interactions between different groups of the stabilizing agents also allow new stabilizing agent-stabilizing agent interactions (Figure 7(b), region delimited by green ellipse), leading to an increasing size of the core@shell structures and consequently lower specific surface area compared with $\mathrm{Fe}_{3} \mathrm{O}_{4} @ \mathrm{TCA}$. Even double layered shells can be imagined partly because the amino groups are in their cationic form and also water molecules can facilitate these interactions.

The as-obtained core@shell nanostructures can be imagined as potential carriers of a wide variety of biological active agents; the loading efficiency and the delivery behavior are controlled and induced due to the shell characteristics. The active agents can be attached to the shell, adsorbed into the magnetic core, or even distributed between the two components of the core@shell structures. These active agents will interact with the shell via hydrophobic or hydrophilic interactions. The use of salicylic acid as capping agent will allow the formation of strong hydrogen bonds with these nanostructures, while in the case of glutamic acid hydrogen bonds as well as electrostatic interactions will be possible, depending on the $\mathrm{pH}$. In both cases covalent bonding of the active agent is possible via the reactive phenolic and carboxylic groups. In the case of trichloroacetic acid, especially hydrophobic and dipole based interactions will appear, but also more complex mechanisms of bonding are possible involving partial/full hydrolysis of the trichloro groups followed by covalent bonding. The main interactions between the shell and the biological active agents are presented in Figure 8 . The overall properties of the drug delivery systems are strongly dependent on many factors including the loading procedures, not only the nature and proportions of the components.

\section{Conclusion}

Three new magnetic nanoparticles were obtained starting from magnetite precursors and adequate stabilizing agents (salicylic acid, glutamic acid, and trichloroacetic acid) by spraying the magnetite precursors into the basic stabilizing agent solution. The results reveal important difference between these MNPs, these differences being induced by the used stabilizing agent. The smallest nanoparticles were obtained in the presence of trichloroacetate ions. The mechanism of formation of these suprastructures is strongly correlated with the end functional groups of the stabilizing agent. Comparing the glutamate and trichloroacetate, from both size and free functional groups, significant differences can be identified. In fact, the entire molecule excepting the carboxylate groups (highlighted with red) ensures the interaction of the stabilizing agent with the magnetic core as represented in Figure 7. It can be concluded that the agglomeration of the stabilized core@shell suprastructure is different because of the very different affinity of these end groups. In the case of glutamic acid, the ammonium and carboxylate groups can further interact and thus lead to larger particles and smaller core@shell structure as highlighted by TEM and HRTEM. The as-obtained nanoparticles are potential contrast agents as well as magnetic carriers of specific drugs for cancer diagnosis and treatments. Further works will be conducted in order to study the biocompatibility, cell internalization, and ability for targeted transport and delivery of various biological active agents including cytostatic drugs. 


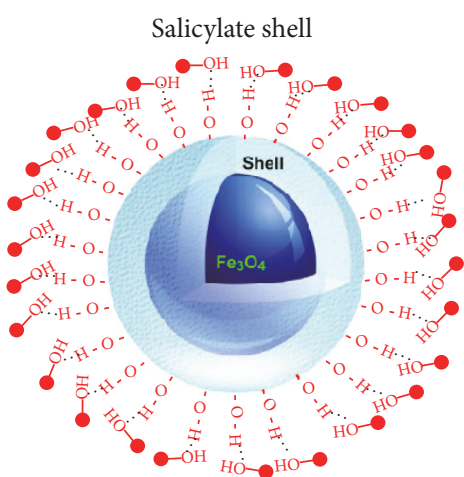

H-bond

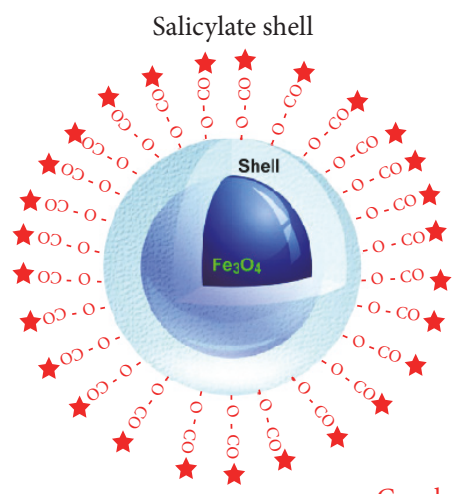

Covalent bonds

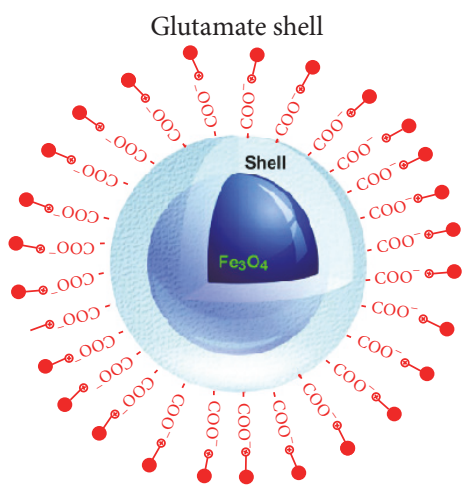

Ionic bond

Electrostatic attraction

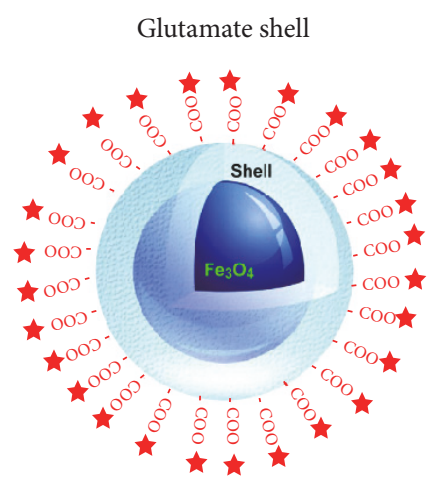

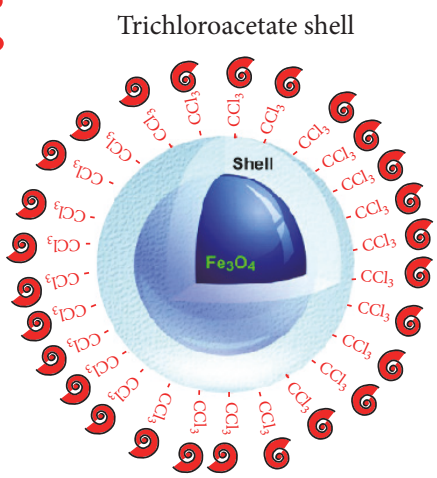

Hydrophobic interaction Dipole-dipole interaction

FIGURE 8: Potential interactions between the nanostructured core@shell structures and different biological active agents.

\section{Conflicts of Interest}

The authors declare that they have no conflicts of interest.

\section{Acknowledgments}

The present work was possible due to the EU-Funding Grant POSCCE-A2O2.2.1-2013-1, Project no. 638/12.03.2014, Code SMIS-CSNR 48652. The financial contribution received from the national project "New Nanostructured Polymeric Composites for Centre Pivot Liners, Centre Plate and Other Components for the Railway Industry (RONERANANOSTRUCT)", no. 18 PTE (PN-III-P2-2.1-PTE-2016-0146), is also acknowledged.

\section{References}

[1] X. W. Lou, L. A. Archer, and Z. Yang, "Hollow micro/nanostructures: synthesis and applications," Advanced Materials, vol. 20, no. 21, pp. 3987-4019, 2008.

[2] H. C. Zeng, "Synthetic architecture of interior space for inorganic nanostructures," Journal of Materials Chemistry, vol. 16, no. 7, pp. 649-662, 2006.

[3] G. Zhang, Y. Liu, C. Zhang et al., "Aqueous immune magnetite nanoparticles for immunoassay," Journal of Nanoparticle Research, vol. 11, no. 2, pp. 441-448, 2009.

[4] M. Tiemann, "Porous metal oxides as gas sensors," Chemistry: A European Journal, vol. 13, no. 30, pp. 8376-8388, 2007.
[5] B. G. Trewyn, S. Giri, I. I. Slowing, and V. S.-Y. Lin, "Mesoporous silica nanoparticle based controlled release, drug delivery, and biosensor systems," Chemical Communications, no. 31, pp. 32363245, 2007.

[6] F. Dong, W. Guo, and C.-S. Ha, "Monodisperse single-crystal mesoporous magnetite nanoparticles induced by nanoscale gas bubbles," Journal of Nanoparticle Research, vol. 14, no. 12, article no. $1303,2012$.

[7] H.-M. Fan, M. Olivo, B. Shuter et al., "Quantum dot capped magnetite nanorings as high performance nanoprobe for multiphoton fluorescence and magnetic resonance imaging," Journal of the American Chemical Society, vol. 132, no. 42, pp. 1480314811, 2010.

[8] S. P. Foy, R. L. Manthe, S. T. Foy, S. Dimitrijevic, N. Krishnamurthy, and V. Labhasetwar, "Optical imaging and magnetic field targeting of magnetic nanoparticles in tumors," ACS Nano, vol. 4, no. 9, pp. 5217-5224, 2010.

[9] H. Gupta, P. Paul, N. Kumar, S. Baxi, and D. P. Das, "One pot synthesis of water-dispersible dehydroascorbic acid coated $\mathrm{Fe} 3 \mathrm{O} 4$ nanoparticles under atmospheric air: blood cell compatibility and enhanced magnetic resonance imaging," Journal of Colloid and Interface Science, vol. 430, pp. 221-228, 2014.

[10] S. Gustafsson, A. Fornara, K. Petersson, C. Johansson, M. Muhammed, and E. Olsson, "Evolution of structural and magnetic properties of magnetite nanoparticles for biomedical applications," Crystal Growth and Design, vol. 10, no. 5, pp. 2278-2284, 2010. 
[11] A. H. Lu, E. L. Salabas, and F. Schüth, "Magnetic nanoparticles: synthesis, protection, functionalization, and application," Angewandte Chemie - International Edition, vol. 46, no. 8, pp. 1222 1244, 2007.

[12] J. Gao, Z. Guo, S. Yu et al., "A novel controlled release systembased homogeneous immunoassay protocol for SCCA using magnetic mesoporous $\mathrm{Fe} 3 \mathrm{O} 4$ as a nanocontainer and aminated polystyrene microspheres as a molecular gate," Biosensors and Bioelectronics, vol. 66, pp. 141-145, 2015.

[13] J. Liu, F. Liu, K. Gao, J. Wu, and D. Xue, "Recent developments in the chemical synthesis of inorganic porous capsules," Journal of Materials Chemistry, vol. 19, no. 34, pp. 6073-6084, 2009.

[14] W. H. Suh, A. R. Jang, Y.-H. Suh, and K. S. Suslick, "Porous, hollow, and ball-in-ball metal oxide microspheres: preparation, endocytosis, and cytotoxicity," Advanced Materials, vol. 18, no. 14, pp. 1832-1837, 2006.

[15] Q. Sun, Z. Ren, R. Wang, W. Chen, and C. Chen, "Magnetite hollow spheres: Solution synthesis, phase formation and magnetic property," Journal of Nanoparticle Research, vol. 13, no. 1, pp. 213-220, 2011.

[16] D. Caruntu, B. L. Cushing, G. Caruntu, and C. J. O'Connor, "Attachment of gold nanograins onto colloidal magnetite nanocrystals," Chemistry of Materials, vol. 17, no. 13, pp. 33983402, 2005.

[17] Y. Li, H. Liao, and Y. Qian, "Hydrothermal synthesis of ultrafine $\alpha-\mathrm{Fe} 2 \mathrm{O} 3$ and $\mathrm{Fe} 3 \mathrm{O} 4$ powders," Materials Research Bulletin, vol. 33, no. 6, pp. 841-844, 1998.

[18] W.-W. Wang and Y.-J. Zhu, "Microwave-assisted synthesis of magnetite nanosheets in mixed solvents of ethylene glycol and water," Current Nanoscience, vol. 3, no. 2, pp. 171-176, 2007.

[19] J. Matutes-Aquino, P. García-Casillas, O. Ayala-Valenzuela, and S. García-García, "Study of iron oxides obtained by decomposition of an organic precursor," Materials Letters, vol. 38, no. 3, pp. 173-177, 1999.

[20] S. Sun and H. Zeng, "Size-controlled synthesis of magnetite nanoparticles," Journal of the American Chemical Society, vol. 124, no. 28, pp. 8204-8205, 2002.

[21] J. Toniolo, A. S. Takimi, M. J. Andrade, R. Bonadiman, and C. P. Bergmann, "Synthesis by the solution combustion process and magnetic properties of iron oxide ( $\mathrm{Fe} 3 \mathrm{O} 4$ and $\alpha$ - $\mathrm{Fe} 2 \mathrm{O} 3$ ) particles," Journal of Materials Science, vol. 42, no. 13, pp. 47854791, 2007.

[22] D. Maity, S.-G. Choo, J. Yi, J. Ding, and J. M. Xue, "Synthesis of magnetite nanoparticles via a solvent-free thermal decomposition route," Journal of Magnetism and Magnetic Materials, vol. 321, no. 9, pp. 1256-1259, 2009.

[23] Y. Liu, W. Zhu, D. Wu, and Q. Wei, "Electrochemical determination of dopamine in the presence of uric acid using palladiumloaded mesoporous Fe3O4 nanoparticles," Measurement: Journal of the International Measurement Confederation, vol. 60, pp. $1-5,2014$.

[24] M. Kumari, C. U. Pittman, and D. Mohan, "Heavy metals [chromium (VI) and lead (II)] removal from water using mesoporous magnetite $\left(\mathrm{Fe}_{3} \mathrm{O}_{4}\right)$ nanospheres," Journal of Colloid and Interface Science, vol. 442, pp. 120-132, 2015.

[25] T. Xia, X. Xu, J. Wang et al., "Facile complex-coprecipitation synthesis of mesoporous $\mathrm{Fe} 3 \mathrm{O} 4$ nanocages and their high lithium storage capacity as anode material for lithium-ion batteries," Electrochimica Acta, vol. 160, pp. 114-122, 2015.

[26] E. Cheraghipour, A. M. Tamaddon, S. Javadpour, and I. J. Bruce, "PEG conjugated citrate-capped magnetite nanoparticles for biomedical applications," Journal of Magnetism and Magnetic Materials, vol. 328, pp. 91-95, 2013.

[27] D. C. Culita, G. Marinescu, L. Patron, O. Carp, C. B. Cizmas, and L. Diamandescu, "Superparamagnetic nanomagnetites modified with histidine and tyrosine," Materials Chemistry and Physics, vol. 111, no. 2-3, pp. 381-385, 2008.

[28] G. Goloverda, B. Jackson, C. Kidd, and V. Kolesnichenko, "Synthesis of ultrasmall magnetic iron oxide nanoparticles and study of their colloid and surface chemistry," Journal of Magnetism and Magnetic Materials, vol. 321, no. 10, pp. 13721376, 2009.

[29] J. Razjouyan, H. Zolata, O. Khayat, F. Nowshiravan, N. Shadanpour, and M. Mohammadnia, "Synthesis and evaluation of radiolabeled, folic acid-PEG conjugated, amino silane coated magnetic nanoparticles in tumor bearing Balb/C mice," Nukleonika, vol. 60, no. 3, pp. 479-502, 2015.

[30] C. Tudisco, M. T. Cambria, F. Sinatra et al., "Multifunctional magnetic nanoparticles for enhanced intracellular drug transport," Journal of Materials Chemistry B, vol. 3, no. 20, pp. 41344145, 2015.

[31] U. Gunduz, T. Keskin, G. Tansik et al., "Idarubicin-loaded folic acid conjugated magnetic nanoparticles as a targetable drug delivery system for breast cancer," Biomedicine and Pharmacotherapy, vol. 68, no. 6, pp. 729-736, 2014.

[32] M. Licciardi, C. Scialabba, G. Cavallaro, C. Sangregorio, E. Fantechi, and G. Giammona, "Cell uptake enhancement of folate targeted polymer coated magnetic nanoparticles," Journal of Biomedical Nanotechnology, vol. 9, no. 6, pp. 949-964, 2013.

[33] D. Rehana, A. K. Haleel, and A. K. Rahiman, "Hydroxy, carboxylic and amino acid functionalized superparamagnetic iron oxide nanoparticles: Synthesis, characterization and in vitro anti-cancer studies," Journal of Chemical Sciences, vol. 127, no. 7, pp. 1155-1166, 2015.

[34] D. Ficai, E. Andronescu, A. Ficai et al., "Synthesis and Characterization of Mesoporous Magnetite Based Nanoparticles," Current Nanoscience, vol. 8, no. 6, pp. 875-879, 2012.

[35] M. Abboud, S. Youssef, J. Podlecki, R. Habchi, G. Germanos, and A. Foucaran, "Superparamagnetic $\mathrm{Fe}_{3} \mathrm{O}_{4}$ nanoparticles, synthesis and surface modification," Materials Science in Semiconductor Processing, vol. 39, pp. 641-648, 2015.

[36] E. Karaoğlu, A. Baykal, H. Erdemi, L. Alpsoy, and H. Sozeri, "Synthesis and characterization of dl-thioctic acid (DLTA)-Fe $3 \mathrm{O} 4$ nanocomposite," Journal of Alloys and Compounds, vol. 509, no. 37, pp. 9218-9225, 2011.

[37] M. Anbarasu, M. Anandan, E. Chinnasamy, V. Gopinath, and K. Balamurugan, "Synthesis and characterization of polyethylene glycol (PEG) coated $\mathrm{Fe}_{3} \mathrm{O}_{4}$ nanoparticles by chemical coprecipitation method for biomedical applications," Spectrochimica Acta-Part A: Molecular and Biomolecular Spectroscopy, vol. 135, pp. 536-539, 2015. 

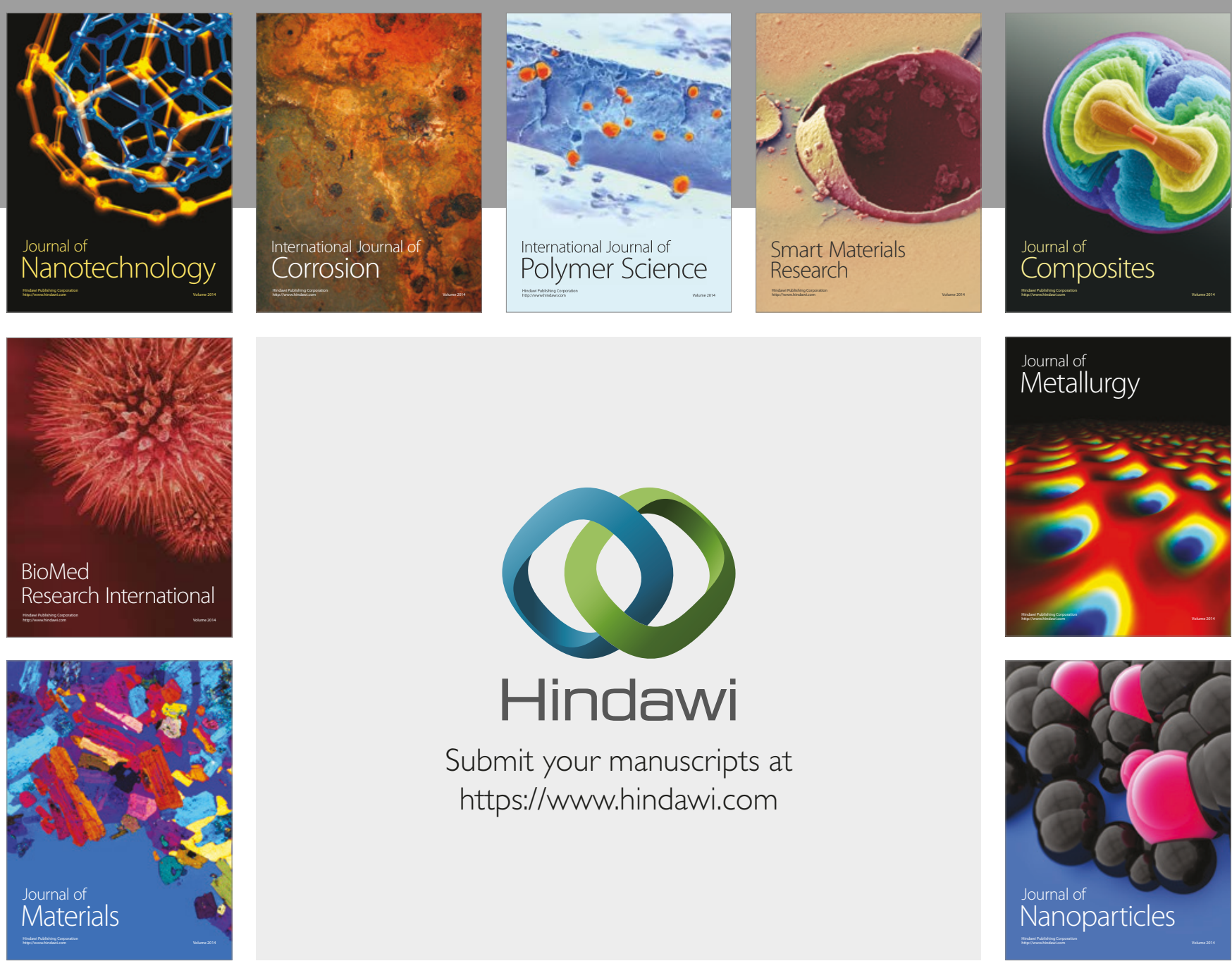

\section{Hindawi}

Submit your manuscripts at

https://www.hindawi.com
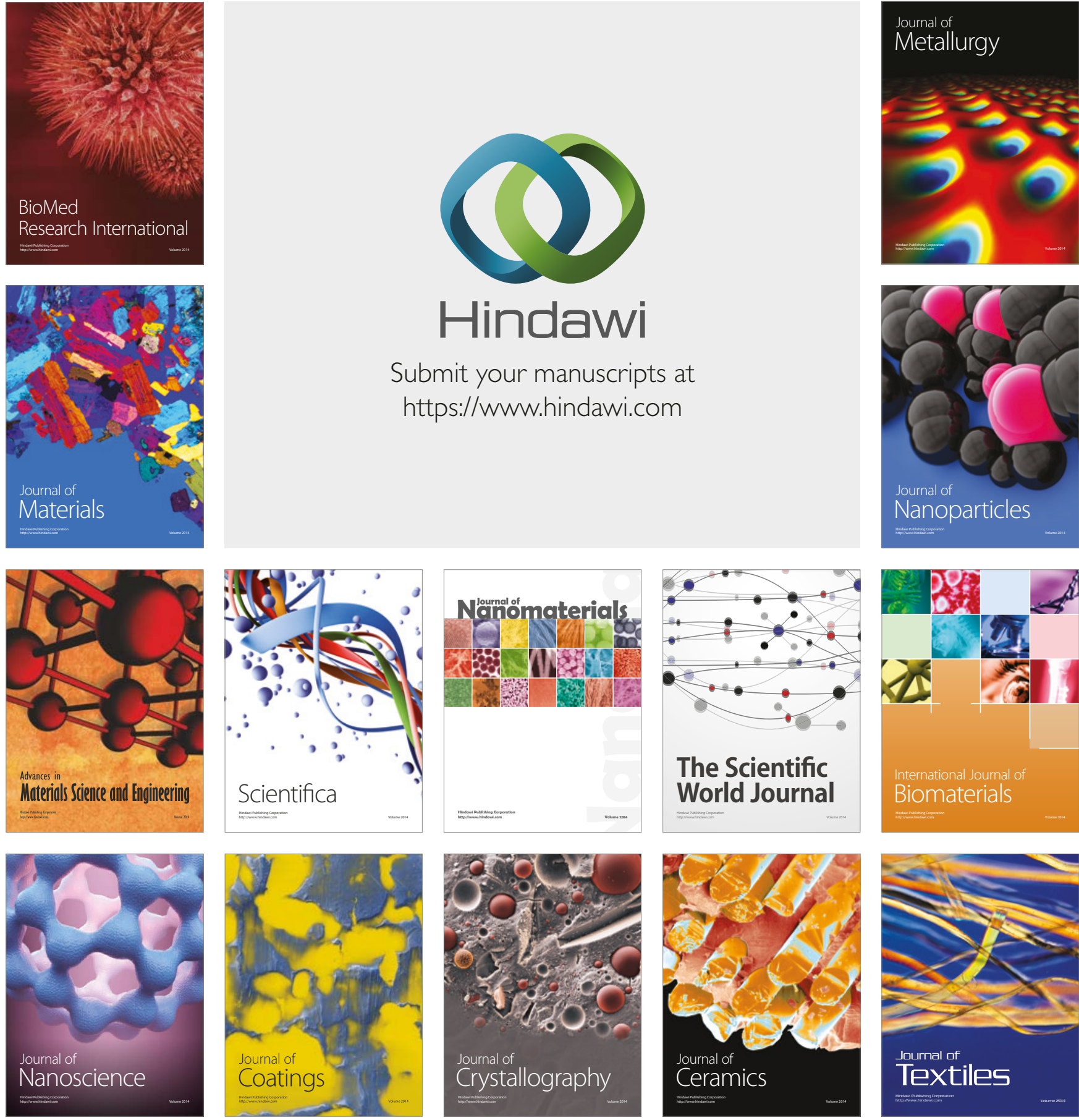

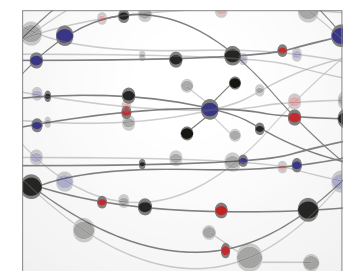

The Scientific World Journal
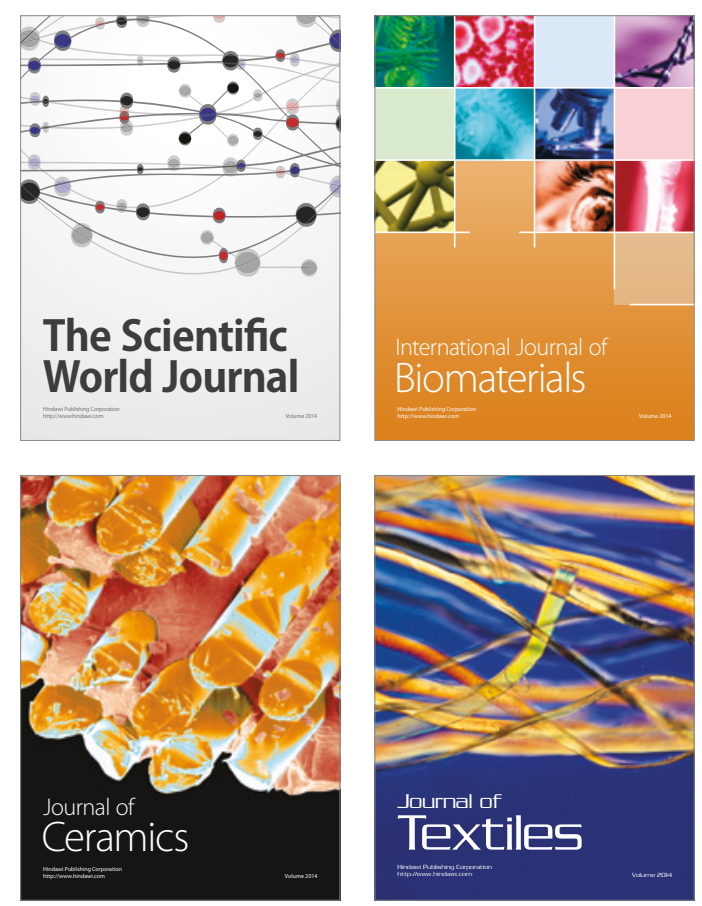